\title{
論文 \\ Two-Dimensional Characteristics of Shallow Water Waves
}

\author{
By Daikaku Manabe and Hirochi ŌHIRA
}

\begin{abstract}
The shallow water channel is often applied to the investigation of the high speed air flow. But the behavior of the shallow water wave is not exactly the same as that of the shock wave in air. This is due to the essential difference of both properties and boundary conditions between the air and the water. This paper presents the information on the two-dimensional characteristics of shallow water waves. Assuming that the disturbance is small, the expression for wave-pattern is analyzed and the effects of the seale, the water-depth, the surface-tension and the velocity are explained. They are compared with the findings of the experiments.
\end{abstract}

\section{Introduction}

It has been known for a long time that there exists an approximate analogy between the twodimensional flow of hypothetic compressible gas with $r=2^{* * *}$ and the flow of sufficiently shallow water on a horizontal plane, and that we can analogize the phenomena in high speed air flow from the results easily obtained in the shallow water channel experiments. The velocity of surface wave and the variation of depth in shallow water correspond to the velocity of sound and the variation of density in air respectively.

Practically, however, their properties and boundary conditions are essentially different, and the effects of the second order quantities ommitted in this analogy are considerable.

In order to utilize the shallow water channel in the best condition or critisize the validity of the experiment with it, it would be needed to have more information on the characteristics of shallow wáter wave.

There are some investigations on the analogy, but almost no essential ones on the two-dimensional flow have been performed.

In this paper, the theoretical analysis on the

- Presented at the Meeting of Japan Society of Aeronautical Engineering in Kyushu District, held at Kyushu University, on Oct 2, 1954. Paper received, Dec. 24, 1954.

* Kyushu Unitersity.

w** $\tau-c v / / v-$ adiabstic constant wave-pattern produced by an aerofoil moving in the shallow water is outlined and the explanation on the effects of the model-size, the water-depth, the surface-tension and the velocity is given. They are compared with the experimental results.

2. Fundamental Equations and Expression for Wave-Pattern

Only an outline of the theory will be given here (the detail is given in ref. 1.) Fig. 1 shows a model moving with uniform velocity $v$ in $x$-direc tion. Its chord-length is $2 i$. The plane $A B, z=$ 0 , is the surface of the undisturbed water and the plane $A^{\prime} B^{\prime}, z=h$, is the bottom. The depth of the still water is $h$.

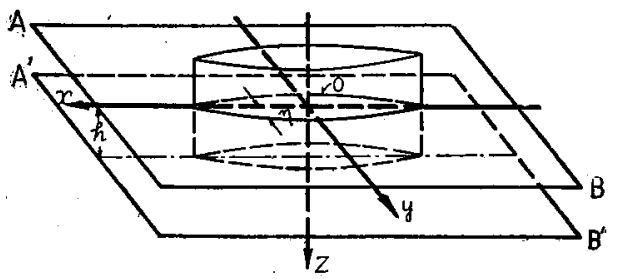

Fig. 1

Now, assuming that the model is thin and the disturbance is small, there exists the velocity potetial $\dot{\phi}$, and we have the following equation for it

$$
\frac{\partial^{2} \phi}{\partial x^{2}}+\frac{\partial^{2} \phi}{\partial y^{2}}+\frac{\partial^{2} \phi}{\partial z^{2}}=0
$$

with the boundary conditions 
at $z=0$ (surface of water):

$$
\frac{v^{2}}{g} \frac{\partial^{2} \phi}{\partial x^{2}}=\left(1-\frac{T}{\rho g} \nabla^{2}\right) \frac{\partial \phi}{\partial z}
$$

at $z=h$ (bottom of water):

$$
\frac{\partial \phi}{\partial z}=0,
$$

at $y=0$ (side face of model):

$$
\frac{\partial \phi}{\partial y}=-v \frac{\partial \eta}{\partial x},
$$

where $g$ is the acceleration of gravity, $T$ the surface tension, $\rho$ the density of water, $\eta$ the ordinate of the side face of model in $y$-direction, and $\nabla^{2} \equiv \frac{\partial^{2}}{\partial x^{2}}+\frac{\partial^{2}}{\partial y^{2}}$

Then we can obtain the solution for the velocity potential $\phi$ which satisfy the above boundary conditions. The surface depression $\zeta$ below the mean level is given from the relation at the free-surface

$$
-\frac{\partial \phi}{\partial z}=v \frac{\partial \zeta}{\partial x}
$$

Then, the expression for the wave-pattern, i. e. the locus of maximum depression, is found.

When the model is of a symmetric cosine-form aerofoil (almost similar to the lenticular one) and has zero incidence, the expression for the wavepattern from the leading edge of the model is given by

$$
\left\{\begin{array}{l}
\frac{x}{l}-1=\beta-\frac{\sqrt{A} B^{\prime}}{A B^{\prime}-A^{\prime} B} \\
\frac{y}{l}=-\beta \frac{A^{\prime} \sqrt{B}}{A B^{\prime}-A^{\prime} B}
\end{array}\right.
$$

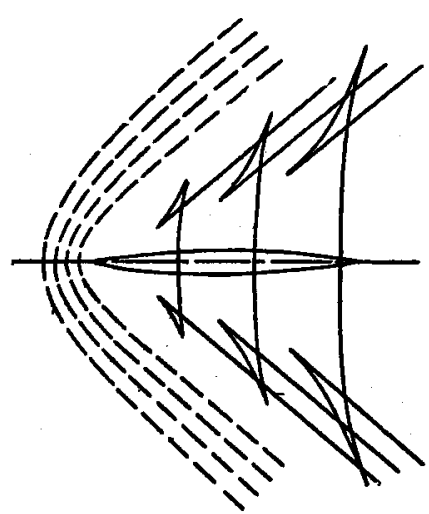

(a) $M<1$

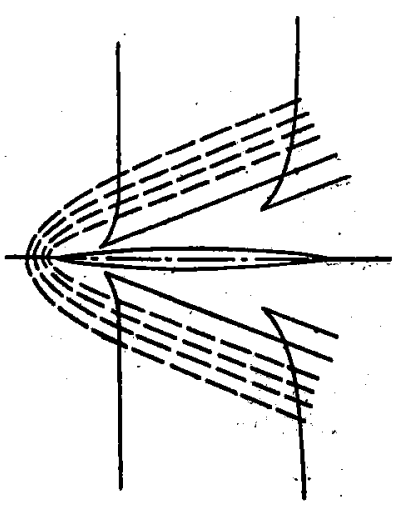

(b) $M=1$ where

$$
\left\{\begin{array}{l}
A=\kappa^{2}\left(1+\mu^{2} u^{2}\right) u \tanh u \\
B=u^{2}-A \\
\beta=\left(\mp \frac{1}{4}+\frac{1}{2}+s\right) \pi \frac{h}{l}, \quad[s=0, \pm 1, \pm 2, \cdots] \\
\kappa^{2}=g h / v^{2} \\
\mu^{2}=T / \rho g h^{2}
\end{array}\right.
$$

Increasing the value of the parameter $u$ in eq. (4), a line, starting from $a$, aft of the nose, to $b, c,, d^{\prime}$, and ending at $e$, fore of the nose, is steadily drawn as shown in Fig. 2. Point $a$ corresponds to the minimum value of $u$, while the point

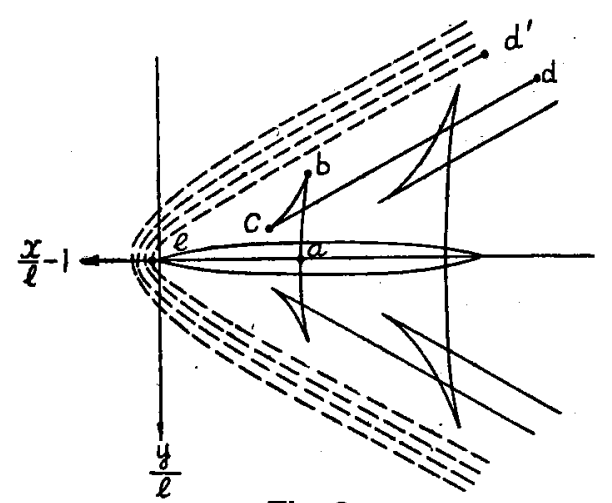

Fig. 2

$e$ to the maximum $u$. Points $d$ and $d^{\prime}$ meet at infinity. For the other values of the integer $s$ in eq. (4), successive lines similar to $a$ to $e$ are also drawn. When the value of 8 is larger, corresponding lines to $d^{\prime} e$ appear in front of $d^{\prime} e$ and those corresponding to ad appear behind ad. These two sets of lines are the top or bottom lines of

Fig. 3. The wave-pattern produced by a cosine-form aerofoil (the surface tension was taken into account). 


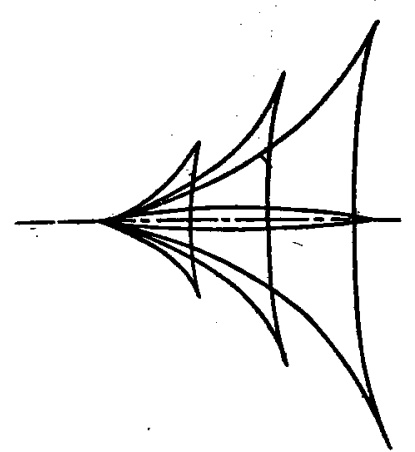

(a) $M<1$

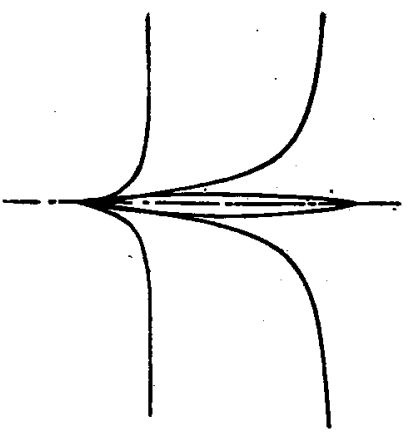

(b) $M=1$

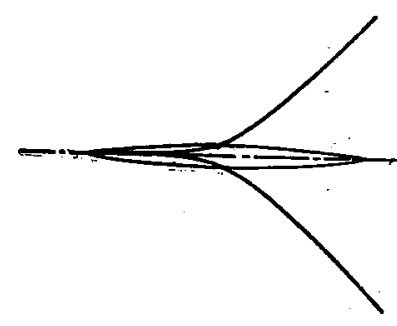

(c) $M>1$

Fig. 4. The wave-pattern produced by a cosine-form aerofoil (the surface tension was neglected).

the periodic waves. The wave-length is short at the fore and long at the aft of the leading edge. Hereafter, for simplicity, we shall call a series of $d^{\prime} e$ lines as the $C$-wave and that of abcd lines as the $G$-wave. The $C$-wave, being of smaller wave-length, is mostly due to the effect of surfacetension while the $G$-wave, being of larger wavelength, is under the effect of gravity.

The deformation of wave-pattern due to the velocity increase is illustrated in Fig. 3. Where the Mach numder $M$ is defined by the ratio of the velocity $v$ of the model to the velocity of propagation of the surface wave with infinitely long wave-length, i. e. $M=v / \sqrt{g h}$. Fig. $3 a$ shows the wave-pattern in so-called subsonic range. As the velocity increases and as the Mach number tends to one, the $C$-wave contracts, i. e. its inclination decreases while the $G$-wave rapidly opens to one another. The distance of points $a$ and $b$ from the leading edge in Fig. 2 becomes large. In Fig. 3b, where $M=1$, these points disappear from sight, and the linear part of the $G$ wave stands at right angles to the direction of motion of the model. In the supersonic range (Fig. 3c), they contract again making the angle $\alpha=\sin ^{-1}(1 / M)$ with the $x$-axis at any distant point on them from the leading edge. This angle is the same as that of Mach angle. If the water is fairly deep and consequently $\mu^{2}$ in eq. (4) can be neglected, we have the similar panorama as shown in Fig. 4. In it, the $C$-wave naturally disappears and there remains the $G$-wave only. The pattern of the $G$-wave is also distorted and point $c$ in Fig. 2 attaches to the leading edge.
The line $c d$ does not appear in it. These waves are deformed in the similar way to those in Fig. 3 as the Mach number increases.

In eq. (4), the parameter $u$ corresponds to $2 \pi h /$ $\lambda$, where $\lambda$ is the wave-length. The velocity of propagation of the surface wave $c$ vs. the wavelength $\lambda$ is shown in Fig. 5 . The minimum and the maximum values of $u$ correspond to $\lambda_{a}$ and $\lambda_{e}$ whose velocities of propagation are the same with that of the model. Accordingly, points $a$

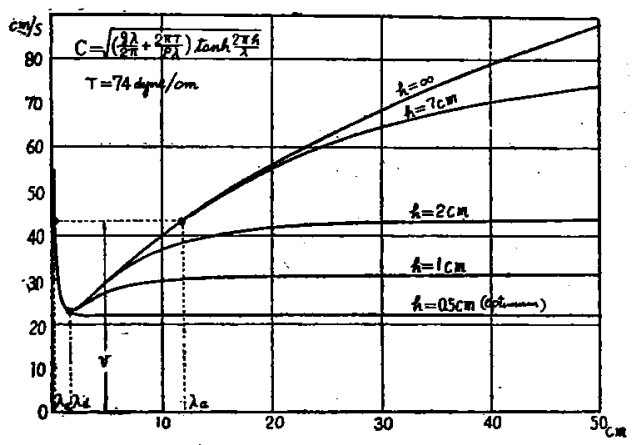

Fig. 5. The velocity of propagation of the surface wave vs. wave-length curve.

and $e$ in Fig. 2 correspond to $\lambda_{a}$ and $\lambda_{e}$ respectively, and points $d$ and $d^{\prime}$ to $\lambda_{d}$ where the $c$ vs! $\lambda$ curve has a horizontal tangent. On the $x$-axis, the $C$-wave has the wave-length $\lambda_{\varepsilon}$ which is approximately given from eq. (4) by

$$
\lambda_{e} \div 2 \pi h \mu^{2} \kappa^{2}
$$

while the wave-length $\lambda_{n}$ of the $G$-wave is obtained from

$$
M^{2} \frac{2 \pi h}{\lambda_{\imath}} \div \tanh \frac{2 \pi h}{\lambda_{1,}}
$$


Our theory and Fig. 5 predict that no waves will be produced provided the model moves with the velocity lower than the minimum velocity of propagation of the surface wave. This condition that the formation of the wave depends on the velocity of the model not on the Mach number will be important.

Now, we shall investigate the effects of the size of the model and the depth. The chord-length $2 l$ is involved in $\beta$ only, i. e. the ordinates of the pattern are inversely proportional to the chord length. Relative to the model, consequently, the pattern is reduced inversely in proportion to the magnifying power of the chord-length. On the water surface, the pattem is not distorted at all, while only the model itself is enlarged. The water-depth is involved in $\beta$ and $\mu^{2}$. If the water is fairly deep, we may neglect $\mu^{2}$. In such a case' the pattern is enlarged in direct proportion to the magnifying power of the depth. If the water is sufficiently shallow, we must take into account the effect of $\mu^{2}$ and it would deform the pattern, although above tendency would be kept to some extent. The thickmess of the model is not involved in eq. (4). As long as this linear theory is valid, however, it acts to linearly increase the magnitude of the surface depression.

\section{Experimental Results ${ }^{2}$ )}

The channel used was of $60 \mathrm{~cm}$ wide and $330 \mathrm{~cm}$ long. Refering to the Laitone's method's, a-part of the bottom below the fixed camera was made of glass. Its cross-section is presented in Fig. 6 . The pictures were taken focussing the camera on the ground-glass screen above the model. In order to obtain almost a parallel light, the carbon arclight was placed at about $4 \mathrm{~m}$ distance from the channel and the light was reflected vertically by

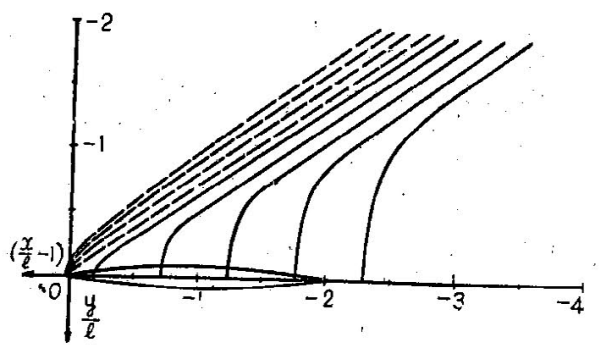

a mirror placed under the channel. The velocity of the model was electrically measured by recording the signals of intermittent current between a brush on the moving. carriage and the terminals on a edge of the channel with the timing by a 500-cycle magnetic tuning-fork.

Figs. 7, 8 and 9 show the variation of the pattern with increasing Mach number around a $10 \%$ thick cosine-form aerofoil with zero incidence. In order to demonstrate the characteristics of shallow water wave exaggeratedly, the water-depth and the chord-length were chosen $h$ $=7.1 \mathrm{~cm}$ and $2 l=20 \mathrm{~cm}$ respectively. The theoretical pattern numerically obtained from eq. (4) were also shown with them.

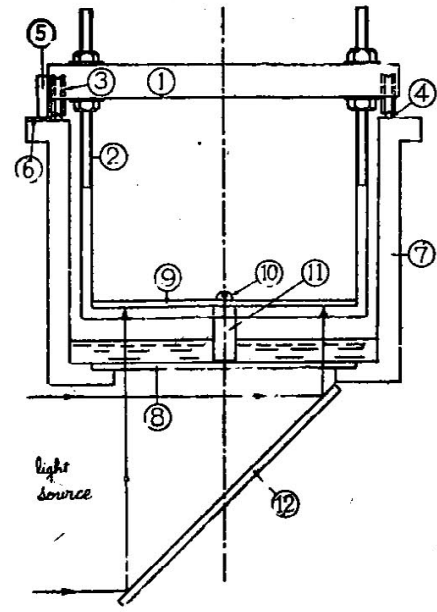

Fig. 6. The cross-sectional view of the channel. (1) : traveling carriage, (2) : arms supporting the screen, (3): wheels, (4): rails, (5): brush, (6): terminals, (7): channel, (8): transparent glass, (9): screen (ground-glass); (10): screw fixing the model, (11): model, (19): mirror.

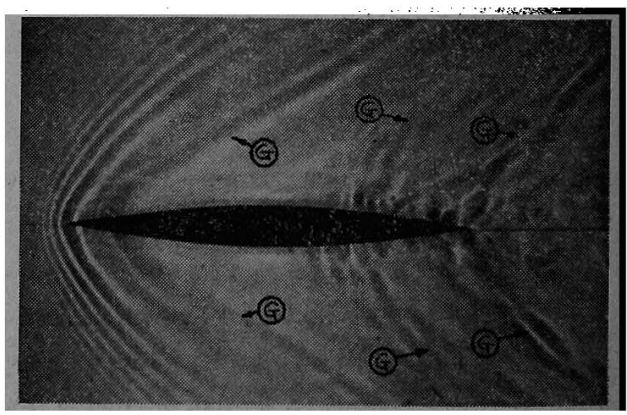

Fig. 7. Cosine-form aerofoil: thickness ratio $10 \%, 2 l=20 \mathrm{~cm}$, incidence $0^{\circ}, h$ $=7.1 \mathrm{~cm}, v=0.41 \mathrm{~m} / \mathrm{s}, M=0.49$. 

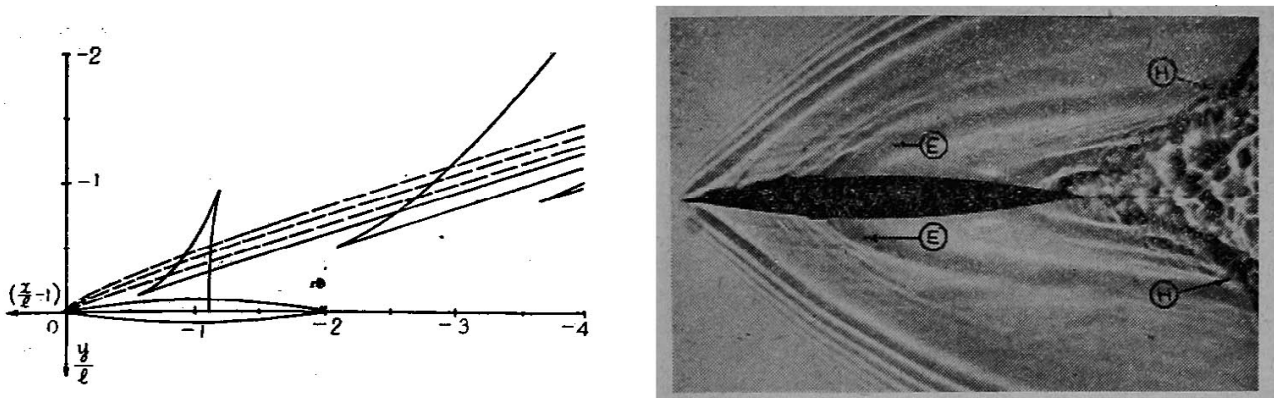

Fig. 8. $v=0.77 \mathrm{~m} / \mathrm{s}, M=0.92$.
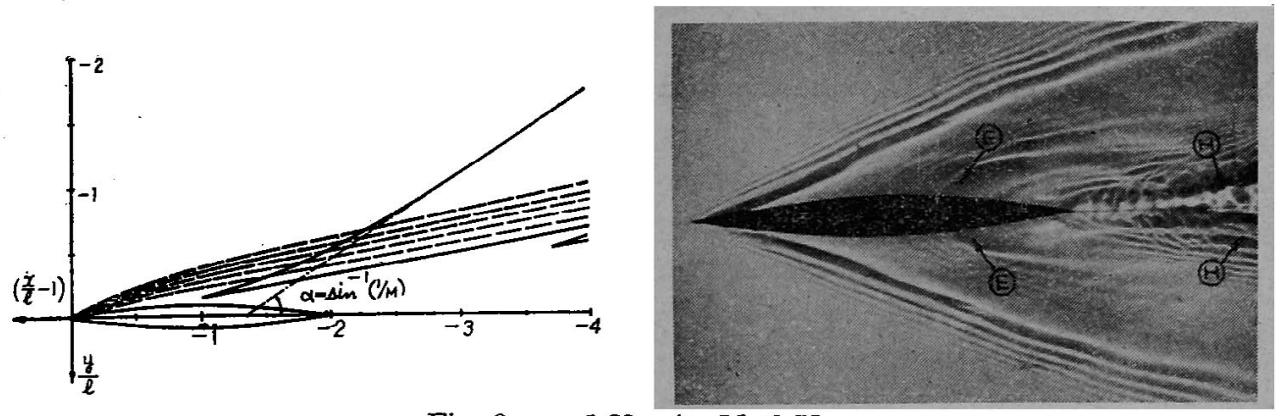

Fig. 9. $v=1.30 \mathrm{~m} / \mathrm{s}, M=1.56$.

In these pietures, we see that the flow is separated at low Mach number but is smooth at high Mach number. This is the similar phenomenon with that in the air and would show the superiority of the high speed performance of this wing aerofoil, although this combination of waterdepth and chord-length invalidate the analogy. The discrepancies from the analogy are the formation of the capillary ripples, the deformation of the shock wave and its periodic occurence, as stated in the previous section.

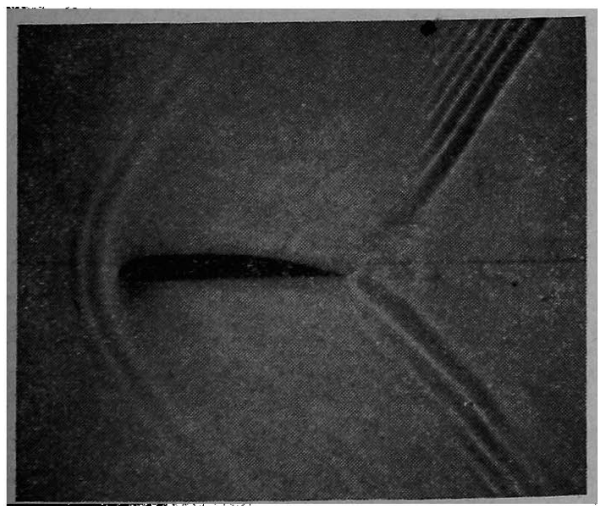

Fig. 10. NACA 4412 : chord-length 10 cm, incidence $0^{3}, h=1.1 \mathrm{~cm}, v=0.29$ $\mathrm{m} / \mathrm{s}, M=0.88$.

A series of white.lines with short wave-length appearing from the leading edge are the top lines of the capillary ripples ( $C$-wave). At great distances from the model, the inclination of the $C$ wave conforms with that of the theoretical pattern and the wave-length is almost constant. Near the model, however, it is pushed forward and the wave-length increases as it approach the nose. This is due to another sort of wave which raise the water surface at the leading edge and lower at the trailing edge. As far as the assumption of small disturbance is valid, this sort of wave would not affect the pattern treated in this paper. But actually this is not so and this intereference occurs. The discrepancy of the pattern from the theoretical one is more manifest at high Mach number than at low one.

In Fig. 7, (G)'s are the $G$-wave and they appear

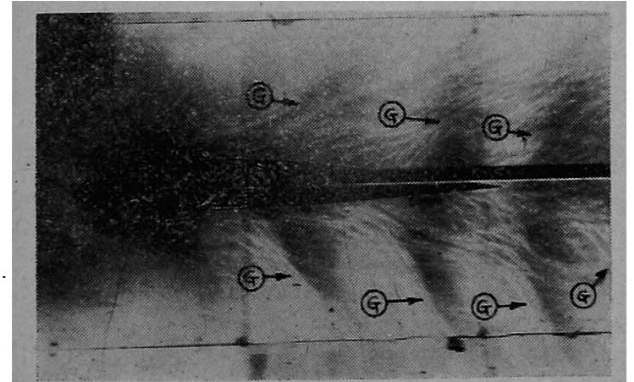

Fig. 11. MAC 86: chord-length $100 \mathrm{~cm}$ incidence $0^{\circ}, h=10 \mathrm{~cm}, M=0.70$.

(by T. Suhara) 
successively. As it is the larger disturbance compared with the $C$-wave, its pattern is more distorted. At such a low speed, there is no constant velocity of propagation of the surface wave. Therefore, these waves are not analongous to the shock waves in the air. In Fig. 8 and 9, the $G$-wave predicted by the theory is not obvious. The expansion waves, (1)'s, are seen at approximately the same location with the front cusp of the theoretical pattern. But the hydraulic jumps, (ii)'s, have similar shape to the theory. It seems that these two waves are related to the successive $G$-waves.

It should be noted that, in Fig. 9, the wave from the leading edge makes much smaller angle with the direction of motion of the model than the Mach angle, while the former is the same or slightly larger than the latter in the air. This is because that the wave from the leading edge is in this case made of the capillary wave whose velocity of propagation has not at all a constant velocity as the sound.

Fig. 10 represents the pattern produced about the NACA 4412 aerofoil. The wave from the leading edge resembles the detached shock, though it is nothing but the $C$-wave. As indicated in the last section, it is formed only when $v$ exceeds the minimum value of $c$, and has no relation with the Mach numder.

In the towing-tank for naval architects, using fairly large models, Dr. Toyotarö Suhara once experimented with various aerofoils*. One of the pictures is shown in Fig. 11. (G)'s periodically formed are the typical $G$-waves shown in Fig. 4a.

* Performed in 1944 at the Aeronautical Engineering Department, Kyushu Imperial University.

\section{Coniclusion}

The fundamental equation of the present theory is based on the assumption that the disturbance is small. This assumption naturally leads to the Laplace's equation instead of the well known equation for the compressible gas involving $\pm\left(1-M^{2}\right)$ as its coefficient. "If the water is sufficiently. $\mathrm{s}$ hallow and the surface depression is no more neglected compared with the depth of the still water, it is, of course, necessary to solve the latter equation.

But it is interesting that our single solution of the former equation covers the complete range of Mach number, subsonic, transonic, or supersonic. Moreover, the $a b$ part of the $G$-wave in Fig. 2, which is most closely analogous to the shock wave, moves from the leading edge to the trailing edge as the velocity of the model increases in the subsonic range, while, when the Mach number exceeds one, the fact that the $b c$ part which is closely equivalent to the shock in supersonic range suddenly appears from the leading edge, is quite similar to the phenomenon found in the air.

\section{Acknowledgment}

We wish to express bearty thanks to Dr. T. Suhara for his encouragement and very useful discussion and also to Dr. Y. Watanabe for making possible this program of experiments.

1) D. Manabe: Theoretical Investigations of the Shallow Water Waves on the Surface of Middle Depth (Part I); Technology Reports of the Kyushu University, Vol. 27. No. 2, July 1954, p. 100 . To be continued,

2) D. Manabe and H. Ohira: On the Shallow Water Waves (I-V), Tech. Rep. Kyushu. Univ. Vol. 26, No. 2,3,4, 1953; Vol. 27, No. 1, 1954: To be continued.

3) E. V. Laitone: A Study of Transonic Gas Dynamics by the Hydraulic Analogy, J. A. S., Apr. 1952, p. 265.

(142頁かららづく)

$\left(f_{1}+\Delta f_{1}\right)=f-\Delta f_{1},\left(f_{2}+\Delta f_{2}\right)-f_{0}=f+\Delta f_{2}$ なる中間 周波数が得られるが，これらは $f$ と大差ないから中心 周波数 $f$ なる共通の中間周波增幅器を通過乙得 $\tau$, 次 に赑検波器に上って2つの中間周波の念周波 $f_{B}=(f$ $\left.+\Delta f_{2}\right)-\left(f-\Delta f_{1}\right)=\Delta f_{1}+\Delta f_{2}$ が検出される. $f \ll f_{0}$, $\Delta f_{1} \div \Delta f_{2}$ だから $f_{B} \div 2 \Delta f_{1}$ となり， $f_{1}$ なた $f_{2}$ を単独に用いる場合の約 2 倍の腍周波数が検出できる
ととるに中間周波增幅は安定になし得る。すし $f_{0}$ を 抑止せずに輻射しその反射波を局部発振波として利用 すると，それにも士 $\Delta f_{0}$ が合まれるのた，両側波と 混合检波された出力からはドップラー効果による周波 数偏移が住とんど消去されてしまう不都合がある。

(谷浩太郎) 